\title{
Volver... ¿a dónde?: personajes desarraigados en la dramaturgia de Roberto Cossa
}

\author{
Yolanda ORTIZ PADILLA \\ Universidad de Jaén \\ yortiz@ujaen.es
}

\begin{abstract}
RESUMEN
El exilio político y económico es una realidad que recorre el teatro de Roberto Cossa, exilio que crea personas y personajes desarraigados, desubicados, que caminan perdidos por el nolugar de sus textos. El lenguaje será la herramienta dramática que dé cuenta de esta nebulosa; la triste carcajada, el efecto producido. Los "tanos"-la nona, monstruo insensible, repite nostálgicamente el nombre de Catanzaro- y los españoles -el padre de Susy en $\mathrm{Ya}$ nadie recuerda a Fréderic Chopin- que poblaron la Argentina, el sainete y el grotesco; que ansiaron siempre el regreso, están en sus textos. Pero Cossa da una vuelta de tuerca al tema de la inmigración para hablarnos, en dos de sus obras - Gris de ausencia y Lejos de aquí-, no ya de estos "tanos" y españoles, sino de sus descendientes, exiliados económicos de la Argentina que soñaron sus padres.
\end{abstract}

Palabras clave: teatro argentino, Roberto Cossa, exilio, lengua, regreso.

\section{Return... to where?: rootless characters in the plays of Roberto Cossa}

\begin{abstract}
The politic and economic exile is a reality that flows through Roberto Cossa's theatre: exile that makes people and characters feel rootless, out of place, and wandering lost along the no-place of his plays. Their native languages and dialectics will be the dramatic tool used for telling this 'ambiguity'; the effect of this tool is a sad laugh. 'Tanos' - as the Nona, insensitive monster that repeats with melancholy the name of Catanzaro- and the Spaniards -as Susy's father in Nobody remembers to Frederic Chopin- appears constantly in Cossa's writings: 'tanos' and Spaish people that settled in Argentina -and also in sainetes and grotesque literature- but always wished to return to their lands. Cossa goes deeper in the immigration topic to talk -in two of his plays: Gray of ausence and Far away from here-not about those Italians and Spaniards, but about their descendents, economically exiled of that Argentina that their parents dreamed about.
\end{abstract}

Key words: argentinean theatre, Roberto Cossa, exile, language, return.

[...] para todos los hombres del mundo que quieran habitar el suelo argentino [...]. El Gobierno Federal fomentará la inmigración europea; y no podrá restringir, 
limitar ni gravar con impuesto alguno la entrada en el territorio argentino de los extranjeros que traigan por objeto labrar la tierra, mejorar la industria e introducir y enseñar las ciencias y las artes (Pérez, 1995: 19).

Estas palabras de la Constitución de 1853 son el instrumento político para llevar a cabo un plan económico en el cual la nueva Argentina "agroexportadora" se proveería de la "capacitada" (Pérez 1995: 19) mano de obra europea ante su desconfianza por la local. Pero, como nos indica el ácido humor de Feinmann, no llegaron los laboriosos y pulcros obreros ingleses que tan ardientemente esperaban los dirigentes de la nación:

Hubo, en nuestras clases dirigentes, tal desprecio por el elemento nativo que, claro, reclamaron a los inmigrantes como condición de posibilidad del despegue histórico de este país. [...] Este suelo estaba no solamente poco poblado, sino, muy especialmente, mal poblado. Poblado por gauchos y por indios. No había otra salida: los argentinos debían descender de los barcos. Debíamos abrirnos a los industriosos hombres de la vieja Europa, a los que quisieran poblar este país mal poblado [...]. Todos lo sabemos: no vinieron los sajones. Llegó la hez, la canalla europea. Llegaron como inmigrantes. Llegaron pobres, harapientos, urdidos por el hambre y las ideas anarquistas y socialistas (Feinmann 2002: 2325)

Y estos "agregaos" (Ordaz 1997: 15) al país tardaron poco en darse cuenta de que la "tierra prometida" no cumplía sus promesas, y que "hacer l'America", en realidad, era sinónimo de trabajo y miseria, difíciles de sobrellevar en medio de la soledad, los anhelos malogrados, la nostalgia, la incomunicación y el desamparo (Pérez 1995: 22). Todo esto hacía, hace, del inmigrante, en palabras de Ordaz: "un ser trágico, un agonista en lucha permanente por su existencia y sus empeños de progresar y triunfar" (Ordaz 1997: 25).

Además, estos extranjeros que, supuestamente, debían forjar la riqueza agropecuaria argentina, se instalaron en su mayoría en la capital, hacinándose en los conventillos de la zona sur y conformando todo un "arrabal quimérico" (Ordaz 1997: 15) en el que las lenguas se fundían y confundían. Cada grupo de inmigrantes, urgido por la necesidad de comunicarse, se lanzó a hablar una media lengua mezcla de su idioma vernáculo y el castellano, que convirtió la ciudad en una segunda Babel. Esta mezcolanza lingüística sería fuente de comicidad para el sainete - de acrítico costumbrismo - y sin perder la sonrisa, aunque ahora confundida con el llanto, en el grotesco criollo y, años más tarde, en la dramaturgia del autor porteño que hoy nos ocupa, Roberto Cossa.

Como iremos comprobando en este artículo para dicho autor la lengua es, por un lado, un medio de caracterización de los personajes y, por otro, un arma de denuncia social, ya que en muchas de sus obras hace de ella el instrumento 
dramático utilizado para dar cuenta del desarraigo y la desubicación de un grupo concreto de personajes, los exiliados. Eso sí, maestro del humor negro le buscará siempre el lado risible a la tragedia, pues considera que la risa nos permite afrontarla - analizarla - sin caer en un vacuo sentimentalismo.

Hasta este punto hemos mencionado los hombres y mujeres reales que conforman el perfil de la Argentina a partir del siglo XIX, ese todo heterogéneo y conflictivo que se crea y se recrea constantemente, sobre unas bases indígenas que fueron prácticamente aniquiladas. Será Ernesto Sábato uno de los intelectuales que mejor dé cuenta de esta compleja realidad argentina:

Pero si la condición catastrófica rige para Europa, para nuestro país rige con mayor fuerza: como integrantes de la civilización que sufre ese cataclismo, tenemos un primer motivo de angustia; pero como pertenecientes a una de las líneas de fractura espacial de esa civilización, tenemos un segundo motivo, que es específicamente nuestro. Estamos en el fin de una doble quiebra en el tiempo y en el espacio, estamos destinados a un experiencia doblemente dramática. Perplejos $\mathrm{y}$ angustiados, somos actores de una oscura tragedia, sin tener detrás el respaldo de una gran cultura indígena (como la azteca o la incaica) y sin poder tampoco reivindicar de modo cabal la tradición de Roma o París (Sábato 2004: 66)

Puesto que este artículo pretende analizar cómo el dramaturgo argentino Roberto Cossa se aproxima en sus textos a esta compleja realidad, a los tipos que de ella resultan, trataremos de construir en los párrafos que siguen una imagen algo más completa de este sujeto que será en gran medida su obsesión y referente teatral.

Si nos alejamos unos pasos para abrir el plano y recoger en nuestro estudio no sólo un país, Argentina, sino el continente latinoamericano completo descubriremos que esta configuración diversa y conflictiva, con matices distintos según la zona, caracteriza la realidad sociocultural de toda Latinoamérica y determina la necesidad que esta tiene de buscar y construir su identidad. Un continente que, marcado por la colonización, vive en un escenario de reiterado y complejo destierro: destierro como pérdida de la tierra en el proceso de colonización; destierro cultural y lingüístico, de lo propiamente indígena, en su dependencia del país colonizador; destierro de aquellos que fueron arrastrados como esclavos y forman hoy la actual Afroamérica; destierro de aquellos europeos que lo eligieron para "hacer l'América" en las sucesivas olas inmigratorias; destierro político en las reiteradas dictaduras; destierro económico por la eterna crisis y dependencia de estos países. Esta experiencia de desplazamiento y pérdida provoca un efecto en la configuración del sujeto, que deja de ser fuerte, sólido y estable para convertirse en un sujeto complejo, disperso y múltiple; un espacio lleno de contradicciones internas que rompe con la imagen romántica del yo. A este sujeto, resultado de la realidad latinoamericana, lo llamará Cornejo Polar (2003), primero "sujeto heterogéneo" y, 
después, en una evolución natural de su pensamiento, "sujeto migrante". Así lo caracteriza el crítico peruano:

¿Realmente podemos hablar de un sujeto latinoamericano único y totalizador? ¿O deberíamos atrevernos a hablar de un sujeto que efectivamente está hecho de la inestable quiebra e intersección de muchas identidades disímiles, oscilantes y heteróclitas? (Cornejo 2003: 14)

Y siendo Roberto Cossa un "psicólogo, buceador" (Castagnino, 1968: 200) de la idiosincrasia latinoamericana, argentina, es lógico que sus personajes participen de este "sujeto heterogéneo", "migrante". En sus textos teatrales lo encontraremos en aquellos personajes que tienen su referente en los inmigrantes de las últimas oleadas que aun permanecen en la Argentina, en aquellos que ya han regresado descubriendo el exilio en su propia patria, en sus hijos, muchos de los cuales son ahora los exilados económicos de la Argentina que soñaron sus padres.

De este "sujeto migrante" que puebla la dramaturgia de Cossa nos interesa precisamente ese tipo específico al que hemos llamado "exiliado económico" y cabría preguntarnos el porqué de esta denominación. Pues bien, porque sin obviar las diferencias entre un inmigrante y un exiliado -las razones políticas del exiliado anulan cualquier alternativa al desplazamiento, el inmigrante camina desposeído de todo halo protector- nosotros trabajaremos precisamente en la difusa frontera que los separa, en la cuota de dolor que los une, que a fin de cuentas, es la que padece cualquier transterrado, y cito a Mora Contreras:

Convendría olvidarse cuanto antes de la diferenciación que parte de la crítica ha hecho entre el destierro motivado por causas económicas y el derivado de causas políticas, que encierra, a mi juicio, una concepción jerárquica y elitista que, además, no se corresponde con la realidad. El trabajador emigra y el intelectual se exilia, como si la cuota de sufrimiento que estos grupos experimentan variara en relación con su estatus (Mora 1998: 288).

Por tanto, al mirar de cerca estos personajes transterrados descubriremos su resistencia a perder la identidad, el desarraigo violento, el despojo y su vivir provisorio, como metido en un paréntesis que sólo se cerrará con el retorno; rasgos específicos que Giella (1994: 191-194) o Rama (1978: 10) atribuyen al exilado político, pero que consideramos están también en los exilados económicos de Cossa, pues como afirma Foster (1994: 191) "luchar por pagar la olla" en ciertos contextos "se vuelve tan subversivo como abogar por la utopía social".

En este estudio intentaremos trazar el círculo de desarraigo del exilado que se cierra, para comenzar de nuevo, precisamente, en el ansiado regreso. Queremos mostrar los mecanismos dramáticos que Cossa utiliza para volcar en sus textos este camino de padecimientos que tiene como meta obsesiva el "volver" del tango. "Volver", sí, ¿pero a dónde? Decíamos más arriba que este "sujeto heterogéneo", 
"migrante", rompe con la imagen romántica del "yo", es decir, rompe con un "yo" lo suficientemente fuerte, sólido y estable como para regresar siempre sobre sí mismo, como para que en el tópico romántico del viaje jamás ponga en cuestión el regreso al punto de partida (Cornejo 2003: 13). Frente a lo que ocurre con este fuerte, sólido y estable sujeto, para muchos de los personajes de la literatura argentina el regreso no es posible. Pongamos como ejemplo al emblemático protagonista de Rayuela, Horacio Oliveira, que aunque se encuentra "Del lado de acá" tras su vida en París siente "no haber vuelto", "estar siempre de ida aunque no supiera adónde" (Cortázar 2003: 48). Este sentimiento también se encuentra en ciertos personajes de Roberto Cossa, precisamente en aquellos en los que descubrimos los ademanes del exiliado. Sus voces, aunque diseminadas en numerosas obras, son las que protagonizan Gris de ausencia $(1981)^{1}$ y Lejos de aqui (1993), pieza esta última que Cossa escribiría junto a Mauricio Kartun.

Decía el novelista Antonio Muñoz Molina en su obra Sefarad que "si viajas solo en un tren o caminas por una calle de una ciudad en la que nadie te conoce no eres nadie: nadie puede averiguar tu angustia" porque "la parte más onerosa de nuestra identidad se sostiene sobre lo que los demás saben o piensan de nosotros" (Muñoz 2006: 37-38). Ante el miedo a perder su identidad los personajes transterrados de Cossa desarrollan un mecanismo de defensa: negar el tiempo presente y todo lo que en él habita, el país en el que se encuentran, su lengua y sus costumbres. Cito al respecto a William Foster:

El exilio se caracteriza por la presencia de la ausencia, por el peso del donde no está uno, de la patria perdida y anhelada, de la memoria cultural y lingüística que se sostiene contra viento y marea, para afirmar con soberbia y posiblemente con alevosía que uno no pertenece al espacio donde se encuentra. Cuando se produce la asimilación, cuando uno se resigna camaleónicamente a ser parte de la vivencia donde se encuentra, se volatiliza la autoidentidad del exilio y los espacios del aquí y de allá se confunden irremediablemente (Foster 1994: 192).

Por esta razón Lorenzo considera inadmisible, protegido por su ridícula máscara grotesca, la comparación entre una tasca madrileña y un bar de Buenos Aires, atrapado en una vida anterior mitificada y convertida en "lo único valioso":

Mercedes. Bueno... Es como ir de tascas.

Lorenzo. (Ofendido.) ¡De tascas...! ¿Qué está diciendo? En un café de Buenos Aires te sentás como un señor... como un caballero. Te pedís un café... que entre paréntesis te lo sirve un gallego... y empiezan a llegar los amigos... y se charla de política... de fútbol... de mujeres ¡Se filosofa! En

${ }^{1}$ Las obras de Roberto Cossa citadas en el presente artículo van acompañadas del año del estreno. 
un bar de Buenos Aires uno aprende sobre la vida. En las tascas de acá están parados, apretados como ganado y hablan a los gritos [...] (Cossa 2004b: 109).

La patética obsesión de los personajes por reproducir los ritos cotidianos, patrones de conducta, que tuvieran un día en su patria, ahora, en su negado espacio del presente, llevará a Adolf Steiner -militar del Tercer Reich que ha naufragado en costas argentinas en Los compadritos (1985)- y a Lorenzo - exiliado argentino en un restaurante de carretera de Madrid en Lejos de aquí (1993)- a ponerse el abrigo; el uno, porque en Alemania es invierno aunque en Argentina sea verano; el otro, porque leyó en el diario que en Buenos Aires estaba lluvioso, aunque en Madrid haga un día radiante:

Manolo. ¿Por qué te has puesto la gabardina? Estamos en mayo.

Lorenzo. En la Argentina es otoño.

Manolo. Pero aquí hace un día radiante.

Lorenzo. En Buenos Aires está lluvioso. Lo leí en el diario.

Manolo. Bueno... Pero podrías ponerte la gabardina al llegar a Buenos Aires.

Lorenzo. Vos dejame a mí. El que se vuelve a Buenos Aires soy yo. Es mi regreso (Cossa 1999: 104-105).

"Lo leí en el diario", dice el personaje, por lo que parece que Lorenzo en Lejos de aquí, al igual que Chilo en Gris de ausencia, uno en España y el otro en Italia, continúan comprando el diario Clarín, como argentinos cabales.

Pero será la palabra el último refugio para la identidad de estos personajes, defendiéndola contra viento y marea. Por eso cuando se resquebraja y empieza a infectarse de acentos o idiomas que no son los suyos, presenciamos en escena cómo se produce un desgarro en el personaje -una pérdida, un despojamiento-, asistimos a la caída de su máscara grotesca y a su caída en el no-lugar, "la tierra de nadie" (Giella, 1994: 185), el "viaje infinito" como afirma Jorge Dubatti (1994-1995: 87) ha comenzado.

Chilo no tuerce ni un ápice su español porteño, al contrario, lo refuerza como seña de identidad, obstinado en no hablar y no querer entender el italiano:

Chilo. ${ }^{[\cdots]} \mathrm{Y}$ encima me insultó

Frida. ¿Cómo te insultó?

Chilo. Y sí... Algo dijo en italiano.

Frida. ¿Qué dijo?

Chilo. No lo entendí (Cossa 2004b: 69).

Bien aferrado a su lengua encontramos también a Lorenzo en Lejos de aquí: 
Lorenzo. ¿Y por qué me hablás en español?

Estela. ¿En qué idioma quieres que te hable?

Lorenzo. i¿Sos española ahora?!

$[\ldots]$

Lorenzo. Vos sos argentina... ¿Me oíste? ¡Argentina! (Cossa 1999: 110)

Pero la máscara cae al final de ambas piezas, y ante estos personajes que se quiebran en escena, el espectador/lector experimenta una desconcertante sensación en la que no puede evitar reírse, participando, al mismo tiempo, de su profunda pérdida; sensación en la que se cifra el contenido grotesco de estas piezas. En la patética escena final de Gris de ausencia, Chilo, dándose cuenta de que su idealizado Buenos Aires se le está empezando a desdibujar en la distancia, se arranca la máscara resignado, para ponerse el poncho y atender a los "tanos de mierda" en perfecto italiano. Lorenzo, que durante sus diecisiete años en Madrid se ha negado a perder la palabra porteña, "se españoliza" al descubrir que una voz argentina, al otro lado del teléfono, pregunta por su cuñado Manolo que viaja hacia Buenos Aires. Manolo regresa a su tierra de exilio donde cree que le pueden quedar más afectos que en su propio país, España. Lorenzo, hace apenas una semana, intentó el ansiado "volver" del tango, pero no encontró a nadie en "su regreso":

\section{([...] En ese momento suena el teléfono. Lorenzo atiende.)}

Lorenzo. Hola... Sí, es la casa de Manuel González. Manolo acaba de salir para el aeropuerto. ¿Quién habla? ¿Mariela Perazzo de la Argentina? (Se españoliza.) Ah... Es que don Manolo acaba de salir para el aeropuerto... Recientito mire... Llega mañana a Buenos Aires... Sí... Vale... ¿La hora....? El vuelo sale a medianoche de aquí. (Escucha.) Y... calcúlele que llega mañana al mediodía... Al mediodía de acá. (Escucha.) Ah... eso de la diferencia de horas es cosa de ustedes. Acá en mi país son las siete de la noche. (Escucha. Se pone tenso.) ¿Lorenzo....? No... No... iAh...! ¿usted dice el cuñado de don Manolo...? No... Hoy no estuvo por aquí... Hace tiempo que no se lo ve. No sabría decirle, señora. ¿Qué quién soy yo? (Breve pausa.) El chaval de estanco. ¡El chaval del estanco! ¡iEl cha-val del es-tan-co, coño!! ¿O en qué idioma estoy hablando? (Cossa 1999: 153).

La nostalgia congela a estos personajes en el recuerdo mitificado de la patria perdida. Congelado está el recuerdo de Lorenzo que nos describe el Buenos Aires de diecisiete años atrás que, a esa altura de la pieza en la que el personaje aún persiste en su autoengaño, espera que lo reciba en el ansiado día de "su regreso":

Mejicano. Bueno. Entonces... A ver: llegada a las ocho de la mañana. ¿Y?

Lorenzo. A las ocho de la mañana... ¡de allá! Entre los trámites... aduana... se hacen las nueve. Me tomo un taxi en Ezeiza y a las diez menos cuarto estoy en Corrientes y Callao. ¡El centro del mundo! Le compro el diario Clarín, al Colorado... el diariero que tiene el puesto justo frente al 
restaurante El Ciervo. (Se imagina el reencuentro.) ¡El Colorado! ¡Lo que va ser cuado me vea! Bue... me pongo el diario bajo el brazo y... a caminar por Corrientes. Tres cuadras hasta el bar Paulista. En el Paulista te podés tomar tres o cuatro cafés... te lees el diario... se te hacen las doce... el vermut en la Paz, que está haciendo cruz con el bar Ramos. A la una y media almuerzo en Los inmortales, en Corrientes entre Uruguay y Talcahuano. Una pizza de ancho con una porción de fainá... ¡la mejor pizza del mundo! (Cossa 1999: 106).

Estas palabras de Lorenzo, pero también las de Chilo y las de otros muchos personajes de Cossa nos trasladan al Buenos Aires eterno de la poesía de Borges, inmóvil y anclado en el tiempo:

Un almacén rosado como revés de naipe brilló y en la trastienda conversaron un truco; el almacén rosado floreció en un compadre, ya patrón de la esquina, ya resentido y duro.

El primer organito salvaba el horizonte con su achacoso porte, su habanera y su gringo. El corralón seguro ya opinaba: Yrigoyen, algún piano mandaba tangos de Saborido.

Una cigarrería sahumó como una rosa el desierto. La tarde se había horneado en ayeres, lo hombre compartieron un pasado ilusorio.

Sólo falto una cosa: la vereda de enfrente.

A mí se me hace cuento que empezó Buenos Aires:

la juzgo tan eterna como el agua y el aire (Borges 1981: 129-130).

Ahora bien, en el teatro de Roberto Cossa esta evasión en un pasado idealizado es una forma de alienación que sitúa a los personajes fuera de la realidad, en ese espacio del recuerdo donde la Argentina, o cualquier otra patria pérdida, se convierten en tierra idílica, pero a la vez, irreal y fantasmagórica. Para el Chilo que está en Roma la bonaerense calle Florida “¡Está llena de flores! Y árboles que se entrecruzan por arriba. Puentecitos... góndolas... músicos y poetas que recitan. Y la gente canta y baila" en "una fiesta interminable" (Cossa 2004b: 73); como las calles del Montmartre recordado por Ivonne, prostituta que va de París a Buenos Aires acompañando a Carlitos en su "volver" tanguero de El viejo criado (1980), para añorar Passy, donde "florecen los cerezos" o el Sena, que "lo pintaron de violeta" (Cossa 2004b: 61-62). El resultado, como vamos viendo, es que Cossa crea en sus textos una atmósfera poética llena de evocaciones, eso sí, nunca exenta de 
patetismo. El autor erige sobre el escenario un espacio de nostalgia que se torna improductiva ya que paraliza a los personajes, les impide afrontar el presente y construir un futuro que esté hecho de algo más que de la añoranza del pasado. El ruso que forma parte del Comité Central del Partido Socialista en El avión negro (1970) evoca el hogar de la infancia:

Ruso. [...] Yo vivía en Varenik, un pueblito de campesinos, cerca de Vladivostok y mi padre nos leía los discursos de Lenin. Nos sentábamos alrededor de la mesa, papá leía y después todos cantábamos (Ruso comienza a tararear una canción nostálgica, pensando en su lejana niñez.) (Cossa 2004a: 33).

El alemán de El tío loco (1982), sin decir una palabra en español, "De pronto se entristece. Quizá se acuerde de su país. Su voz adquiere el tono de un lamento y termina llorando" (Cossa, 2004b: 142). Hasta la nona, vieja italiana impasible ante todo lo que no sea comida, repite el nombre de su ciudad natal "Catanzaro" (Cossa 2004a: 107)

Siguiendo a Giella podemos decir que en el exilado "se produce una inversión del curso natural de la temporalidad. Se anclan en el pasado, ven el futuro como un regreso y cortan la posibilidad de nuevos horizontes" (Giella, 1994: 194). Y así, viven $\sin$ arraigarse, sin entregarse, pues todo lo han ido haciendo de manera condicional (Ordaz, 1997: 19), como parte de un camino cuya meta es "volver". "Dentro de un año termino de pagar todas la deudas, vendo mi parte y me vuelvo a España" (Cossa, 2005: 93) dice Don Bouza, el mozo gallego de Los días de Julián Bisbal (1966). Otro gallego, el padre de Susy en Ya nadie recuerda a Frederic Chopin (1982), uno de los tantos anarquistas que se bajaron de los barcos para poblar la Argentina, también sueña con el regreso:

Padre. [...] Cuando seas grande, Susy, te llevaré a conocer mi pueblo. Es un lugar pequeñito, rodeado de montañas. Desde la ventana de mi pieza se ve un camino que llega hasta el cielo. Cuando todo cambie en España irás a conocer mi pueblo [...] (Cossa 2004b: 88).

Y también volvería Camila, "la tana" que limpia los baños en El sur y después (1987), si tuviera, claro, dinero para el pasaje.

Fermin. ¿Qué te pasa, tana? ¿Por qué no te volvés a Italia, eh?

Camila. (Por lo bajo) Dame la plata para el pasaque... (Cossa 2004b: 268).

Cossa le da una vuelta de tuerca al exilio mostrado en el sainete y en el grotesco criollo al cumplir, muchos de sus personajes, el sueño del regreso. En el presente trabajo los acompañamos en su tortuoso camino hacia la meta y llegamos con ellos a su tierra natal para descubrir, una vez allí, que "volver" no los ha transformado, continúan siendo unos exilados, eso sí, ahora en su propia patria. De este modo 
Roberto Cossa parece situar a muchos de sus personajes en el "desexilio", concepto que Mario Benedetti (1986: 41) desarrolló tanto en sus ensayos como en su poesía:

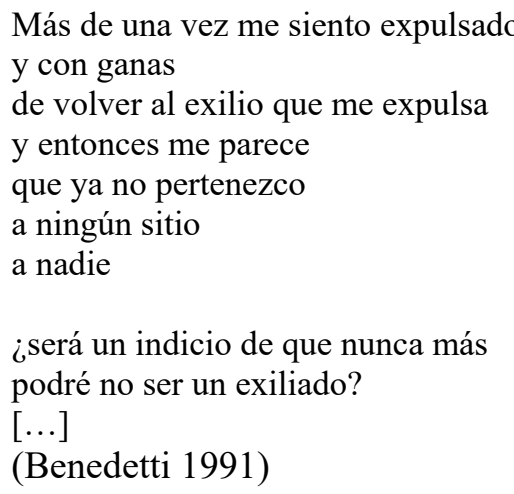

Cossa "desarticula el mito del regreso", nos dice Dubatti (1994-1995: 87), y que mejor ejemplo que Carlitos que en su "volver" tanguero ni siquiera encuentra "el viejo criado" que lo reciba, entre otras cosas, porque a los viejos criados ahora les resulta más rentable trabajar en una fábrica. Tras cuarenta años en París esperando que sus sienes estuvieran plateadas, regresa y descubre que el Buenos Aires mítico del tango y el recuerdo no existe.

Manolo, tras treinta años "juntando plata y odio"(Cossa 1999: 118) en Buenos Aires, regresa a España para montar "Pampas Argentinas" un restaurante en el que se sirve comida típica del Río de la Plata, como en la "Trattoría la Argentina" de Dante y Lucía en Roma. Manolo en Lejos de aqui y Dante y Lucía en Gris de ausencia se encuentran en su tierra natal reproduciendo los mismos patrones de conducta que tuvieran en su anterior exilio: trabajo, miseria, ahorro meticuloso y, en suma, una lucha por la superación y la supervivencia, solo que ahora lo hacen en suelo patrio.

$\mathrm{Y}$ ante ello nos preguntamos, ¿esta pequeña Babel que es la "Trattoría la Argentina", es el lugar de Dante y de Lucía? La palabra, medio de comunicación y último reducto para la identidad del exilado, infectada por nuevos acentos -Frida adopta el español de España- y transformada en nuevos idiomas -Martín ha perdido su lengua materna, y con ella la posibilidad de comunicarse con su familia- se convierte ahora en factor de incomunicación y disociación entre los personajes, en símbolo de su profundo desarraigo.

Lucía (Al teléfono.). ¡Martincito! Figlio mío. ¿Come vai? (Pausa.) ¡Qué come vai! (Escucha con un gesto de impotencia.) ¡Ma non ti capisco, figlio mío! ¿Come? ¿Come? ¿Mader? ¿Quí è mader? ¡Ah... mader! Sí, sono io. ¡Mader! (Dirá todo lo que sigue llorando y sin parar.) Ho nostalgia di te. ¿Quando verrai a vedermi? ¿Fa molto freddo a Londra? (Escucha.) 
¿Come? ¿Come? ¿Cosa è "andertan”? (A Frida.) Diche que "no andertan" (Cossa 2004b: 74).

Al final de Lejos de aquí, nos damos cuenta de que Manolo ha tratado de disimular su desarraigo, repitiéndole a Estela, repitiéndose, "Pero si podemos ser felices... ¡Coño...! ¡Se trabaja bien!” (Cossa, 1999: 120). Pero sin ella, no le queda nada en su "primer mundo". Quizás Argentina no es su lugar, pero España tampoco, y en una nueva vuelta de tuerca a la primitiva utopía del exilado, Cossa monta a Manolo en un avión hacia Buenos Aires: el lugar del exilio, preso ya de la "contranostalgia" de su "desexilio, "la curiosa nostalgia del exilio en plena patria" (Benedetti 1986: 41). Quizás Dubatti tenía razón y el "viaje infinito" ha comenzado, justo en el momento en el que los personajes descubren que ya no son de ningún sitio y por lo tanto no existe el lugar al que "volver".

Lorenzo. Te podías volver a Vigo...

Manolo. Cuando me fui tenía diez años... ¿Qué voy a hacer en Vigo? En Buenos Aires al menos tengo... bueno, recuerdos... amigos.... [...] (Cossa 1999: 150).

También Lorenzo, "desexiliado", participa de esta "contranostalgia", porque cumplido su ansiado regreso se descubre en Buenos Aires, tan extranjero como en cualquier sitio, incapaz de reconocerse en su propia patria. Sin un amigo que cargue "con la parte más onerosa de su identidad", sin un rostro en el que reflejarse, Lorenzo no es nadie y se halla irremisiblemente perdido en tierra de nadie. Por eso, iniciado también su "viaje infinito", regresa a Madrid, la que fuera su tierra de exilio, sin salir del aeropuerto porteño de Ezeiza.

Lorenzo. Volví. (Manolo lo mira.) Ya volví.

[...]

Lorenzo. Hace una semana estuve en Buenos Aires... El jueves pasado, justo a esta hora, estaba en Ezeiza.

$[\ldots]$

Lorenzo. Me temblaban las piernas... Miré por los vidrios... El crepúsculo de Buenos Aires... Casi me pongo a llorar. Un montón de gente saludando en las puertas. La bienvenida, ¿viste...? Aparecieron las valijas en la cinta transportadora... La gente agarró las valijas y fue saliendo con los carritos. Se abrazaban... Puro beso... A mí no me esperaba nadie. ¿Quién me iba a esperar....? Habían pasado diecisiete años. ¿Qué hago acá?, me dije. ¡La pregunta...! ¿Qué boludo! Se fueron yendo todos. El hall quedó medio vacío... Quedamos yo y cuatro coreanos, un matrimonio con dos hijos... Asustados. Miraban todo... Vieras la carita... Estoy igual que ellos, carajo, pensé. "Lo mismo que un inmigrante coreano..." Nos mirábamos con los tipos... Iguales... Ellos y yo estábamos iguales... De pronto aparecieron otros chinos que lo venían a recibir. Se habían retrasado, se ve... ¡Se 
reían...! ¡Se tocaban...! ¡Vieras la alegría de los tipos...! ¡Una fiesta...! Se los llevaron. Me hacían así cuando se iban. Me quedé solo. Las dos valijas dando vuelta en la cinta. Vaya a saber qué se me dio por... Me puse a llorar como un pelotudo... Me di media vuelta y me volví (Cossa 1999: 151)

El Abuelo, personaje perdido en el "gris de ausencia del tango", recrea en su nebulosa memoria una geografía imaginaria en la que se mezclan Roma y Buenos Aires, que se convierte en la máxima expresión del no-lugar sobre el que caminan todos estos personajes que han completado -iniciado- con su regreso, el círculo del desarraigo. “¿Cuándo vamo a volver a Italia, don Pascual?” repetía el viejo en Buenos Aires; “¿Cuándo vamo a volver a Buenosaria, Chilo?” (Cossa 2004b: 71) le dice a su hijo en Roma; para terminar la pieza con su "¿Cuándo vamo a volver a Italia, don Pascual?'(Cossa 2004b: 78) pero ahora en Italia, convertido ya en símbolo cabal de la desubicación y el desamparo del exilado y en el personaje que creemos mejor encarna a ese "sujeto heterogéneo", "migrante", que definíamos al principio de este artículo, ese sujeto "hecho de la inestable quiebra e intersección de muchas identidades disímiles, oscilantes y heteróclitas" (Cornejo 2003: 14)

Sólo Don Pascual aparece inmutable en el recuerdo del abuelo; a Manolo ya no le queda nada en España sin Estela; la "Trattoría la Argentina" no es el hogar de Dante y Lucía, si en él ni tan siquiera pueden comunicarse con sus hijos; Lorenzo regresó a Madrid porque nadie lo esperaba en Buenos Aires. Este sabor amargo que nos dejan los personajes "desarraigados" de la dramaturgia de Cossa nos remite a un cuento de la autora uruguaya Cristina Peri Rossi titulado precisamente "Los desarraigados" y que bien puede servir de conclusión para este artículo:

Una vez que se han perdido, las raíces son irrecuperables. En vano el desarraigado permanece varias horas parado en una esquina, junto a un árbol, contemplando de soslayo esos largos apéndices que unen la planta con la tierra: las raíces no son contagiosas ni se adhieren a un cuerpo extraño. Otros piensan que permaneciendo mucho tiempo en la misma ciudad o país es posible que alguna vez les sean concedidas unas raíces postizas, unas raíces de plástico, por ejemplo, pero ninguna ciudad es tan generosa (Peri Rossi 2007: 72).

\section{BIBLIOGRAFÍA}

BENEDETTI, Mario.

1986 "El desexilio", en Mario Benedetti. El desexilio y otras conjeturas. Buenos Aires: Nueva Imagen, pp. 39-42.

1991 "Pero vengo", en Mario Benedetti. Soledades de Babel. Madrid: Visor. 
BORGES, Jorge Luis.

1981 “Jorge Luis Borges", en José Olivio Jiménez (ed.). Antología de la poesía hispanoamericana contemporánea: 1914-1970. Madrid: Alianza, pp. 129-130.

CASTAGNINO, Raúl Héctor.

1968 Literatura dramática argentina. Buenos Aires: Pleamar.

Cossa, Roberto.

1996 Los compadritos, en Roberto Cossa, Teatro 4. Buenos Aires: Ediciones de la Flor, pp. 123-204.

2004a La nona, en Roberto Cossa, Teatro 2. Buenos Aires: Ediciones de la Flor, pp. 67-136

2004a El avión negro, en Roberto Cossa, Teatro 2. Buenos Aires: Ediciones de la Flor, pp. 11-66.

2004b El viejo criado, en Roberto Cossa, Teatro 3. Buenos Aires: Ediciones de la Flor, pp. 11-64.

2004b Gris de ausencia, en Roberto Cossa, Teatro 3. Buenos Aires: Ediciones de la Flor, pp. 65-78.

2004b El tío loco, en Roberto Cossa, Teatro 3. Buenos Aires: Ediciones de la Flor, pp. 121-142.

2004b El sur y después, en Roberto Cossa, Teatro 3. Buenos Aires: Ediciones de la Flor, pp. 243-300.

2005 Los días de Julián Bisbal, en Roberto Cossa, Teatro 1. Buenos Aires: Ediciones de la Flor, pp. 85-142.

COSSA, Roberto y Mauricio KARTUN.

1999 Lejos de aqui, en Roberto Cossa, Teatro 5. Buenos Aires: Ediciones de la Flor, pp. 97-153

CORNEJO POLAR, Antonio.

2003 Escribir en el aire. Ensayo sobre la heterogeneidad socio-cultural en las literaturas andinas. Lima-Berkeley: Latinoamericana editores.

CORTÁZAR, Julio.

2003 Rayuela. Madrid: Cátedra.

DUBATTI, Jorge.

1994 "Lejos de aquí: inmigración y neogrotesco", Conjunto, $\mathrm{n}^{\circ}$ 100, diciembre 1994-enero1995, pp. 85-88.

FeInMANN, José Pablo.

2002 "Improbables reflexiones acerca de la clase obrera", en José Pablo Feinmann. Escritos imprudentes. Argentina, el horizonte y el abismo. Buenos Aires: Grupo Editorial Norma, pp. 23-30.

FOSTER, David William.

1994 "Espacio escénico y lenguaje", en Osvaldo Pellettieri (ed.). De Lope de Vega a Roberto Cossa. Buenos Aires: Galerna, pp. 189-205. 
GiELLA, Miguel Ángel.

1994 "Inmigración y exilio: el limbo del lenguaje", en Miguel Ángel Giella. De dramaturgos: Teatro Latinoamericano Actual. Buenos Aires: Corregidor, pp. 177-189.

1994 “Transculturación y exilio: La otra orilla de Jorge Díaz”, en Miguel Ángel Giella. De dramaturgos: Teatro Latinoamericano Actual. Buenos Aires: Corregidor, pp. 190-207.

MORA CONTRERAS, Francisco J.

1998 "Exilio y nostalgia en la poesía de Mario Benedetti", en Carmen Alemany, Remedios Mataix y José Carlos Rovira (eds.). Mario Benedetti: inventario cómplice. Alicante: Universidad de Alicante, pp. 286-302.

MUÑOZ MOLINA, Antonio.

2006 Sefarad. Madrid: Punto de lectura.

ORDAZ, Luís. Inmigración.

1997 Escena nacional y figuraciones de la tanguería. Buenos Aires: Editores de América Latina.

PERI ROSSI, Cristina.

2007 "Los desarraigados", en Cristina Peri Rossi. Cuentos reunidos. Barcelona: Lumen, pp. 71-72.

PÉREZ, Irene.

1995 "Introducción", en Irene Pérez (ed. y pról.), El grotesco criollo: Discépolo-Cossa. Buenos Aires: Ediciones COLIHUE, pp. 19-66.

RAMA, Ángel.

1978 "La riesgosa navegación del escritor exiliado", Nueva sociedad, $\mathrm{n}^{\mathrm{o}}$ 35, Marzo-Abril de 1978, pp. 10.

SÁBATO, Ernesto.

2004 El escritor y sus fantasmas. Barcelona: Seix Barral.

TRASTOY, Beatriz.

1999 "La inmigración italiana en el teatro de Roberto Cossa: El revés de la trama" en Osvaldo Pellettieri (ed.). Inmigración italiana y teatro argentino. Cuadernos GETEA $n^{\circ}$ 10. Buenos Aires: Galerna, pp. 137-145.

1987 "Nuevas tendencias en la escena argentina: El neogrotesco", Espacio de crítica e investigación teatral, año 2, $\mathrm{n}^{\mathrm{o}} 3$, diciembre de 1987, pp. 99-105. 